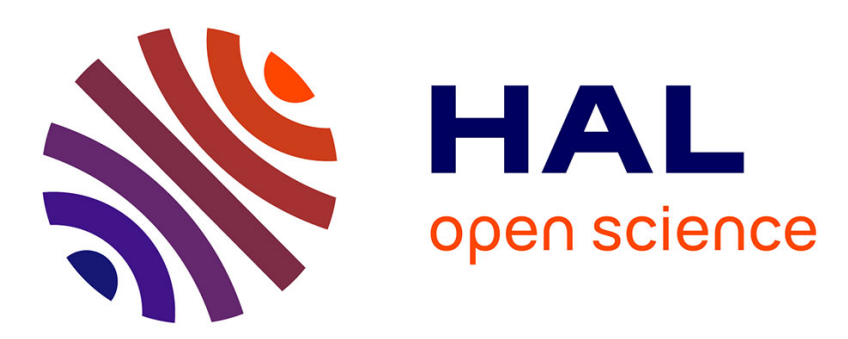

\title{
Co-development of Conceptual Understanding and Critical Attitude: Analyzing texts on radiocarbon dating
}

Nicolas Décamp, Laurence Viennot

\section{To cite this version:}

Nicolas Décamp, Laurence Viennot. Co-development of Conceptual Understanding and Critical Attitude: Analyzing texts on radiocarbon dating. International Journal of Science Education, 2015, 37 (12), pp.2038-2063. 10.1080/09500693.2015.1061720 . hal-01740671

\section{HAL Id: hal-01740671 \\ https://hal.science/hal-01740671}

Submitted on 22 Mar 2018

HAL is a multi-disciplinary open access archive for the deposit and dissemination of scientific research documents, whether they are published or not. The documents may come from teaching and research institutions in France or abroad, or from public or private research centers.
L'archive ouverte pluridisciplinaire HAL, est destinée au dépôt et à la diffusion de documents scientifiques de niveau recherche, publiés ou non, émanant des établissements d'enseignement et de recherche français ou étrangers, des laboratoires publics ou privés. 


\title{
Co-development of conceptual understanding and critical attitude: analysing texts on radiocarbon dating
}

Nicolas Décamp and Laurence Viennot

LDAR Laboratoire André Revuz EA 4434

http://dx.doi.org/10.1080/09500693.2015.1061720

\begin{abstract}
This research documents the impact of a teaching interview aimed at developing a critical attitude in students, and focused on a particular topic: radiocarbon dating. This teaching interview is designed to have students react to limited written explanations of the phenomenon under study, and to express their possible frustration or intellectual satisfaction in relation to these texts. We aim to document the possible link between students' developing conceptual understanding of a topic and their ability to express their frustration when presented with very incomplete explanations, or their intellectual satisfaction when presented with complete explanation. As a side product we intend to observe some of their a priori ideas concerning this topic. Ten teaching interviews conducted with fourth-year university students were recorded, transcribed and coded. Beyond a series of results concerning students' a priori understanding of the domain, the analysis of the interviews suggests that, when students are presented with texts of increasing completeness and discuss these with the interviewer, their critical reactions evolve in time in a very specific way. We propose a tentative model for this co-evolution of student conceptual command and critical stance. The discussion bears on possible interpretations for the "anesthesia of judgment" observed in most students at the beginning of the interview, and for a few of them throughout the discussion. Keeping in mind the "competence vs concepts" current alternative, the conditions that seem to free students' critical potential are analysed in relation to their evolving command of the topic and their degree of intellectual satisfaction.
\end{abstract}

Keywords: Physics education, critical attitude, intellectual satisfaction

\section{Introduction}

In recent years, it has been strongly advocated that the objectives of science teaching might be more profitably defined in terms of various skills rather than of a corpus of contents. Most prominently, inquiry skills have been put to the fore (NRC, 1996) and impressively reactivated in the last decade (Rocard et al., 2007; Osborne \& Dillon, 2008). Here, the focus is on critical faculties and on students' ability to benefit from texts which are available in non-formal contexts (including the internet). Reasons for common acceptance of this type of 
objective are multiple. In a changing world, it may seem impossible to teach directly all the knowledge that will be useful to future scientists. Therefore students preparing for this career should learn how to continuously adapt to new conceptual needs. As for laymen, the main goal should be to enable them to exert a responsible citizenship. For all, a critical attitude and a sense of scientific rationality appear as essential intellectual resources. Moreover, teaching contents per se may be seen as too difficult for students, thereby discouraging these from engaging with science. Defining objectives in terms of skills would then be a detour to avoid the complexity of contents commonly taught in so-called "traditional" courses.

Several questions then arise. One, to put it briefly, is whether the contents will naturally follow the skills. Some beliefs have been commonly expressed in this respect. The most optimistic reports (Rocard et al., 2007) e. g. suggested that, were inquiry skills appropriately developed, then the road would be paved for students' easy access to "science learning", a somewhat undefined concept which should not, however, totally exclude conceptual achievement. In a more controlled register, numerous investigations (e.g. Kirschner, Sweller, \& Clark, 2006; Furtak, Seidel, Iverson, \& Briggs, 2012; Minner, Levy, Century, 2009) now document the conceptual outcome of "Inquiry Based" sequences, and the need to scaffold students to be learning in these contexts. A second question that may be considered linked to the first one is whether there is a correlation between conceptual command and a certain skill. This question has been documented concerning argumentation skills, but no consensus was found (Kuhn, 1991). Drawing on previous research in our group, we would like to put a third question. In several studies (Viennot, L., 2006; Mathé \& Viennot, L., 2009; Feller, Colin, \& Viennot, L., 2009), we observed that some students presented with inconsistent explanations were at first uncritical - only saying that they could not understand the argument -, but the same students expressed a firm critique once they themselves more deeply understood the topic, thanks to the interviewer. What makes this result non-obvious is that students' knowledge in the beginning of this interaction was, in principle, sufficient to detect the inconsistency of the text under study. Consequently, we would like to examine in more detail to what extent students' critical stance may change in time during a discussion with an interviewer, a discussion which is intended to gradually nourish students' comprehension of a given content. We chose the particular topic of radiocarbon dating because it sounds rather familiar whereas constructing what we consider a "minimum" explanation for it is far from obvious.

\section{Rationale}

Our main concern is a possible entanglement between students' developing comprehension of a topic and their ability to criticize a very incomplete and/or inconsistent explanation.

In the context of this study, what we mean by "critical stance" or "critical faculty" does not cover the whole range of understandings encountered in research literature. The meaning we ascribe here to these expressions relies on an epistemological position. We see physics as a science aiming at a coherent and parsimonious description of the world, a few laws accounting for a large set of phenomena in a specified range of validity (Ogborn, 1997, Jenkins 2007). In such a framework, a minimum critical faculty means to be able to detect self contradictory statements or statements that contradict basic laws of physics, and also to pinpoint very incomplete explanations. These contradictions or incompleteness may be detectable with more or less simple lines of reasoning. In our case, we envisage situations where the debatable statements can be identified based on a very simple argument, the adjective "simple" being referred to what is reasonably expectable from the concerned population.

It is worth noting that, in so doing, we leave aside a large part of what is defined as critical thinking by cognitive scientists, who utilize very wide definitions. For instance in Willingham's definition, critical thinking concerns "critical reasoning, decision making and problem solving” (Willingham 2007, author's emphasis) and is characterized by three key features-effectiveness, novelty and self direction. Ennis (1992)'s 
definition states that "critical thinking is the correct assessing of statements" whereas McPeck chooses a more domain-specific but still very large definition: 'the appropriate use of reflective scepticism within the problem area under consideration' (McPeck, 1981, quoted by Moore 2004)

We also leave aside a large part of what is often looked into, concerning students' ability to criticise public accounts of science. Indeed, as has been argued by Jiménez-Aleixandre (2007, see also Jiménez-Aleixandre \& Erduran 2007), several components of critical analysis can be envisaged. Among these is the ability to criticize the sources of the texts under consideration with respect to possible asymmetric relationships of power. Clearly, this critical analysis of the status of experts (Walton 1996, see also Habermas 1981) is not included in our perspective, nor do we consider other abilities such as those listed by Jiménez-Aleixandre \& Puig (2009).

We chose to examine students' expressions of a critical stance in relation to their metacognitive attitudes. In Flavell's words (1987), "Metacognition refers to learners' views and beliefs about learning and to the active regulation of their learning processes". Concerning the links between critical thinking and metacognition, we note that they are not necessarily acknowledged explicitly. For instance in a recent review about metacognition (Zohar and Barzilai, 2013), the expressions "critical thinking", "critical faculty" or any equivalent ones are absent from the paper. In contrast, "critical thinking" is one of the "learning activities" explicitly referred to metacognition by Vermunt (1996). We share this view and we see critical stance as a component of metacognition, i.e. as an essential condition for an active self-regulation of one's own learning processes.

More precisely, we think that expressing dissatisfaction with an explanation requires several conditions. One, of course, is to be able to say: 'Yes, but I don't understand why ...'. Such an awareness of one's own state of comprehension can be qualified as "metacognitive". On a more affective register, it is worth noting that asking questions to reach a sounder comprehension constitutes an exacting approach. We suggest that such an attitude is likely to be related to a search for intellectual satisfaction This might be defined as "a feeling linked to the impression of having understood a complex topic to a certain extent, one that can be identified quite clearly, this being accomplished with a good quality/cost ratio" (Mathé \& Viennot, L., 2009). Note that we do not consider here a kind of motivation that would be necessary for students to engage with physics, but a feeling that should be a product of learning (Viennot, L., 2006). We will therefore be attentive to the extent to which the intellectual path proposed to interviewees may, or may not, foster their "intellectual satisfaction", despite non-negligible obstacles.

We see these - metacognitive and affective - components of students' critical attitude as a priori difficult to unravel. Moreover, these are to be completed by, at least, psychological aspects such as self-esteem. Here, we will refer to "meta-cognitive-affective aspects ( $\mathrm{mca}$ )" to designate the set of indicators we chose to characterise students' critical attitude. We will try to find to what extent these $m c a$ aspects evolve during a discussion intended to nourish a more complete comprehension of the topic in students.

We chose to conduct an investigation using teaching interviews (Komorek \& Duit, 2004) which take the form of a discussion that is orientated towards intellectual acquisition, a discussion that is strongly structured and guided, and allows students to expose their initial thoughts and their reactions to various questions and requests. Consequently, we don't consider that such a "teaching interview" directly provides the pattern for a possible sequence. Rather, we propose this intellectual pathway to students in order to obtain a preliminary access to some aspects of their common reactions.

Concerning the conceptual aspects, the students' initial state of knowledge will also be documented, but as a side product. The emphasis being on $m c a$ aspects and on their evolution during the discussion, we chose not to let the investigation about students' previous ideas take the leading role. Nor will we evaluate formally the students' level of comprehension at the end of the interview. However, students' ideas about radiocarbon 
dating are not much documented in the research literature, to our knowledge. Therefore it may seem worth reporting our limited results, which we will present before those concerning our main focus.

Thus, we see our research design as twofold.

On the one hand, we observe - without pursuing with an inquisitive approach- some aspects of students' views that can be referred to categories concerning their previous understanding of the addressed content. The elements of description then collected might be qualified as "static", i.e. describing a previous "state" of understanding of the interviewees, like in innumerable investigations listed in Duit (2009). They focus on what is often presented as students" "common" ideas, or, in a phenomenographic perspective (Marton 1981,1986; Marton. \& Booth 1997), "variations in understandings", that is, a way to describe commonalities in a large group. These accounts of students ways of thinking can be seen as parts of a relatively selfconsistent student model, like in Vosniadou's perspective (Vosniadou 2002), or as witnessing a "knowledge in pieces", in diSessa's terms $(1983,2008)$. As far as we are concerned, we choose to focus on common ways of reasoning that can be observed in different physical contexts. Such is the case of linear causal reasoning (Fauconnet 1984, Driver et al. 1985, Rozier and Viennot, L. 1991, Viennot, L. 1988, 2001) currently observed in the analysis of systemic situations (Colin 2011, Besson et al. 2010). We also pay special attention to students' preference for an additive or subtractive approach to a phenomenon rather than for a multiplicative approach (Viennot, L. and de Hosson, 2012, 2015).

On the other hand, we capture students' response to a series of explanations, starting with a very incomplete argument, then pursuing with more and more complete explanations. We characterized these responses in terms of degrees of acceptance, of questioning attitude and of (dis)satisfaction. It is noteworthy that we are, this time, more directly confronted to the specificity of individual responses, even if, in the end, we attempt to construct a hypothetic generality.

What mainly characterises this investigation is our focus on the interplay between the developments of students' comprehension of a topic and their critical attitude, in other terms their "intellectual dynamics". We underline that the question addressed in our study is not that of a possible correlation between conceptual command and critical faculty as it concerns a process of co-development, not just a co-occurrence. The indicators which we retained to characterize students' "intellectual dynamics" will be described below. As suggested by this label, the chronology of students' responses plays an important role in our data processing.

\section{Radiocarbon dating: a coherent explanation}

Such a topic may be dealt with at different levels of completeness. We chose to characterize a first level of comprehension that would be self-consistent.

Radiocarbon dating is based on two observations: one is that the proportion of ${ }^{14} \mathrm{C}$ (relative to ${ }^{12} \mathrm{C}$ ) is uniform and constant over time in the atmosphere and the other one is that it decreases in dead organic matter. We assume here that the proportion of ${ }^{14} \mathrm{C}$ in the atmosphere is equal to that in living organic matter (which implies that exchanges between atmosphere and living beings do not depend on the carbon isotope). The number of ${ }^{14} \mathrm{C}$ atoms decreases according to a known law, here an exponential decay law: $N_{C}(t)=$ $N_{0} \exp (-t / \tau)$. This law can be used to compute the time that elapsed between the body's death and the time the sample is collected, provided that we know $N_{0}$ (number of atoms of ${ }^{14} \mathrm{C}$ possessed at death). The fact that ${ }^{14} \mathrm{C}$ concentration is broadly constant in the atmosphere (assumption made by Libby, 1960) is related to equal time rates of formation and disintegration. Such an equality is not accidental. ${ }^{14} \mathrm{C}$ is formed thanks to the 
action of "cosmic" neutrons on nitrogen atoms. When ${ }^{14} \mathrm{C}$ decays, it gives rise back to nitrogen. Thus, if we consider the total sum of all nitrogen (population 1) and ${ }^{14} \mathrm{C}$ (population 2) atoms of the atmosphere, this sum is constant because the process of creation and decay of ${ }^{14} \mathrm{C}$ correspond to exchanges between populations 1 and 2. The ${ }^{14} \mathrm{C}$ time rate of decay $\left(\frac{d N_{C}}{d t}\right)$ is multiplicative (it is given by the product of the number of ${ }^{14} \mathrm{C}$ atoms by the probability of decay by unit of time). Thus, this time rate adjusts until the total number of atoms of ${ }^{14} \mathrm{C}$ in the atmosphere reaches a steady state. Note that understanding the present constancy in time of the ${ }^{14} \mathrm{C} /{ }^{12} \mathrm{C}$ proportion implies understanding that it has not always been the case. To understand this, assume that the population of ${ }^{14} \mathrm{C}$ and ${ }^{14} \mathrm{~N}$ are, respectively, higher and smaller than at steady state. Then the time rates of decay and formation of ${ }^{14} \mathrm{C}$ due to multiplicative structure become, respectively, greater and smaller. As a result the net time rate of change of ${ }^{14} \mathrm{C}$ is negative and the population of ${ }^{14} \mathrm{C}$ will decrease. This process continues until the two time rates adjust. An analogy in order to understand this point is shown in Box 1.

Box 1. An analogy to underline the multiplicative aspect of this topic

In this analogy, the total number of inhabitants in a country is stable and is divided into two categories: rural (representing, for example, carbon-14 atoms) and urban (representing here the nitrogen atoms). We assume that each year $10 \%$ of city dwellers decide to go and live in the countryside and $40 \%$ of rural inhabitants decide to go and live in the city. The situation can be represented by the graph of Figure 1.

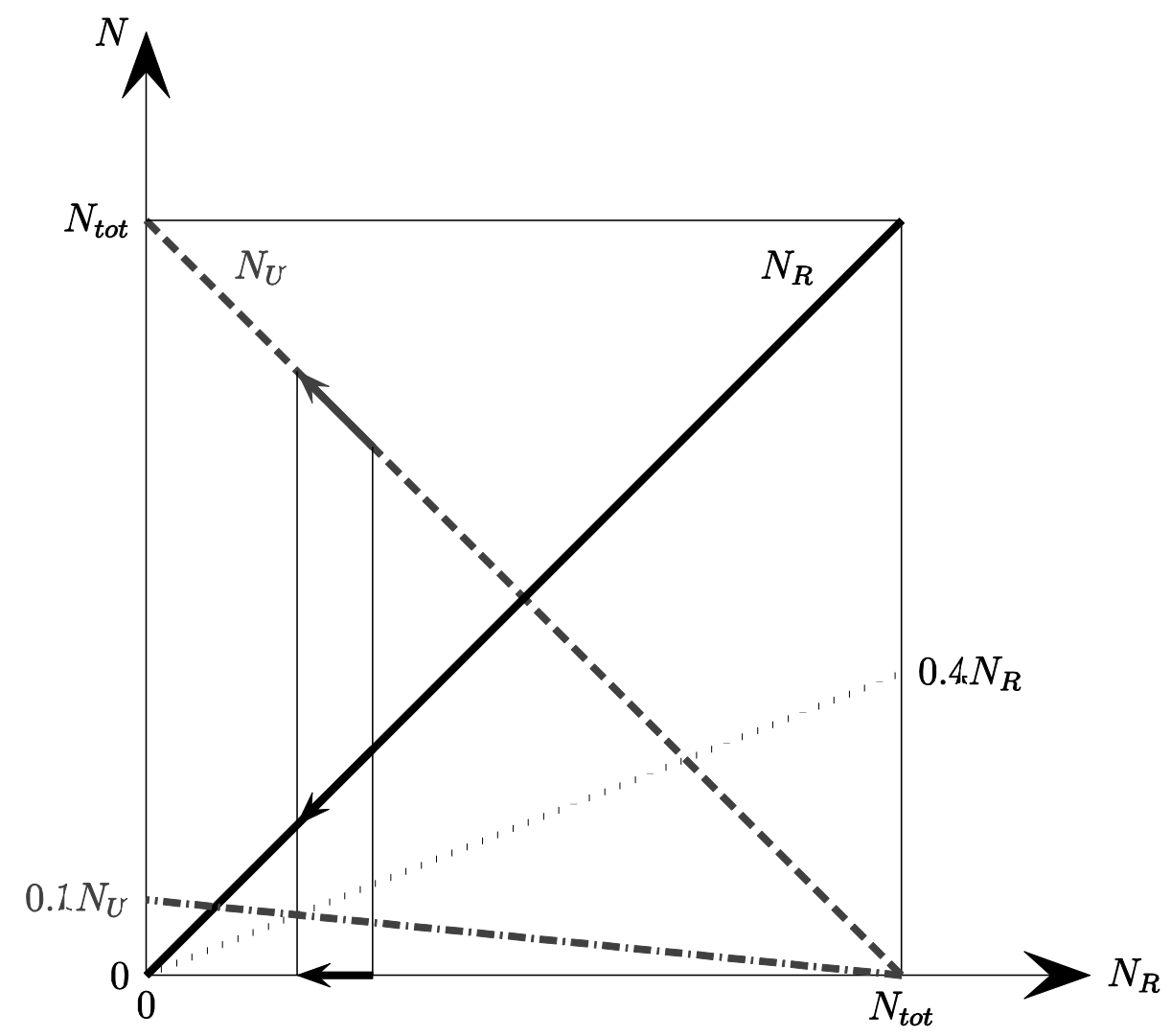

Figure 1: The population analogy. The solid line $\left(N_{R}\right)$ and the dashed line $\left(N_{U}\right)$ represent two complementary population: rural and urban dwellers. The dotted line $\left(0.4 N_{R}\right)$ and the dot-dashed line $\left(0.1 N_{U}\right)$ represent the annual total amount of rural dwellers leaving the countryside and of urban dwellers leaving the city. The 
intersection of these last two lines corresponds to a steady-state.

The total population is $N_{\text {tot }}$. The horizontal axis is the number of rural dwellers. The black solid line represents the number $N_{R}$ of rural dwellers (this is a line of slope 1) and the gray dashed line represents the number $N_{U}$ of urban dwellers (as it is complementary to the number of rural dwellers, the number of urban dwellers is 0 when $N_{R}=N_{\text {tot }}$ and is $N_{\text {tot }}$ when $N_{R}=0$ ). The black dotted line shows the annual time rate at which rural dwellers leave the countryside $\left(0.4 N_{R}\right)$, and the gray dot-dashed line is the time rate at which city-dwellers go to the countryside $\left(0.1 N_{U}\right)$.

We can start from any distribution of the initial population (here initially $N_{R}=0.3 N_{\text {tot }}$ and $N_{U}=0.7 N_{\text {tot }}$ ). We see that this corresponds to an annual time rate of rural dwellers leaving the countryside higher than the annual time rate of the urban dwellers leaving the city $\left(0.4 \times 0.3 N_{\text {tot }}>0.1 \times 0.7 N_{\text {tot }}\right)$, i.e., the rural population decreases and that of cities increases. We immediately see on the graph that this situation will continue until the two rates become equal. And this happens when $0.4 N_{R}=0.1 N_{U}=0.1\left(N_{\text {tot }}-N_{R}\right)$ so when $N_{R}=0.2 N_{\text {tot }}$ et $N_{U}=0.8 N_{\text {tot }}$. This situation is formally similar to the atmospheric ${ }^{14} \mathrm{C}$ evolution but the time rates are different.

\section{Research method}

The interviewsOur centering on students" "intellectual dynamics" added to in-depth analysis of long interviews meet the requirements of "teaching interviews" (Komorek \& Duit 2004). To conduct such an investigation, we needed to address students of a relatively high academic level. We interviewed individually ten prospective physics and chemistry teachers in their fourth year at University (University Paris Diderot, France). In their first years, they took and graduated in the same topics as all physics students. Thus, these students can be considered as very likely to have been taught radioactive phenomena previously.Our target being students' "intellectual dynamics", we needed to find some markers of students' conceptual equipment at a given time, in relation to possible changes in their critical stance. This had to be done without explicitly tracking students' understanding at a given time, not to screen the other aspects $(\mathrm{mca})$ that we were exploring. We didn't find any methodological approach, in research literature, that would be appropriate to this goal and we had to invent a research method. The interviews where framed on a series of five texts (T1 to T5) found on the internet or in popularization literature, plus a final explanation by the interviewer (we call this "text" T6 in what follows). Starting from a very incomplete argument (T1, discussed in Step 1)), the interviewees were successively presented with more and more complete explanations (Steps 2 to 5) until Step 6, with T6, during which they were confronted with the analogy outlined in Box 1. At this step, they have been presented with all the arguments that are necessary to grasp the explanation displayed in the previous section. Table 1 shows which of the crucial elements of explanation pinpointed above (in italics in previous section) are added each time to the preceding text in the considered series. 


\begin{tabular}{|c|c|c|c|c|c|c|}
\hline Arguments & T1 & $\mathrm{T} 2$ & T3 & T4 & T5 & T6 \\
\hline${ }^{14} \mathrm{C}$ decay after death; known law. & $x$ & & & & & \\
\hline $\begin{array}{l}\text { Creation process: « cosmic » } \\
\text { neutron on nitrogen }\end{array}$ & $\mathrm{X}$ & & & & & \\
\hline Need: $\mathrm{N}_{0}$ death known & & $x$ & & & & \\
\hline $\begin{array}{l}{ }^{14} \mathrm{C} /{ }^{12} \mathrm{C} \text { ratio is uniform in } \\
\text { atmosphere and in living beings }{ }^{1}\end{array}$ & & $\mathrm{X}$ & & & & \\
\hline Exponential decay law & & $\mathrm{X}$ & & & & \\
\hline $\begin{array}{l}{ }^{14} \mathrm{C} /{ }^{12} \mathrm{C} \text { ratio in living beings is } \\
\text { constant in time }\end{array}$ & & $x$ & $\mathrm{x}$ & & & \\
\hline $\begin{array}{l}\text { Rate of creation }\left(\mathrm{d}^{14} \mathrm{C} / \mathrm{dt}\right) \text { is } \\
\text { constant in time }\end{array}$ & & & $x$ & & & \\
\hline${ }^{14} \mathrm{C}$ produces nitrogen & & & $*$ & & & \\
\hline Decay vs creation: same rate & & & & $\mathrm{X}$ & & \\
\hline Same rate $->$ steady state & & & & & $\mathrm{X}$ & \\
\hline Transit. regime, adjustment & & & & & $x$ & $\mathrm{X}$ \\
\hline $\mathrm{N}$ and ${ }^{14} \mathrm{C}$ : sum is constant in time & & & & & & $\mathrm{X}$ \\
\hline $\begin{array}{l}\text { Multiplicative }{ }^{14} \mathrm{C} \text { decay rate. } \\
\text { Adaptation through factor } \mathrm{N}_{0}\end{array}$ & & & & & & $\mathrm{X}$ \\
\hline
\end{tabular}

*: this argument is not retained in the text but is provided by the interviewer in case the student ignores it.

Table 1: The texts used in the interviews: arguments successively introduced, this is done explicitly (X), or a hint is provided $(\mathrm{x})$.

We do not claim that students really appropriate each new explicative element provided by the successive texts. Thus, when speaking of students' conceptual development in what follows, we refer to a hypothetical aspect of their intellectual pathway. But at least can we say that, at each step, the discussion has a very good chance to be enriched on a conceptual plane.

After a brief dialogue about their knowledge of radiocarbon dating, the interviewees are asked, at each step, about their reaction to the corresponding text: do they consider it a satisfactory explanation, do they need more arguments and why?

A final step consists in asking students for their global evaluation of the teaching interview, their feeling at the end. Students are asked to formulate their level of satisfaction, to be rated from 1 (poor) to 4 (very high), or to express it in a sentence should they prefer to.

\footnotetext{
${ }^{1}$ In case of questions, the interviewer states isotopic independence during exchanges between atmosphere and living organisms.
} 
More detail is provided in the next section concerning the styles of interaction that characterize the steps in the interview.

\begin{tabular}{|c|c|c|}
\hline Phase & What students are asked for & $\begin{array}{l}\text { Main aspects of the discussion } \\
\text { (planned and/or expected) }\end{array}$ \\
\hline $\begin{array}{l}\text { Step } 1 \\
\text { (T1) }\end{array}$ & $\begin{array}{l}\text { Students are presented with the problem: } \\
\text { what justifies the method used for } \\
\text { radiocarbon dating? Have you heard about } \\
\text { radiocarbon dating ... Read T1 ... } \\
\text { What do you think? Need more? } \\
\text {. }\end{array}$ & $\begin{array}{l}\text { The students appropriate the problem and } \\
\text { recall what they know. First observation of } \\
\text { their reactions. The interviewer is attentive to } \\
\text { students arguments, "mca " reactions, } \\
\text { questions. Low input from interviewer }\end{array}$ \\
\hline $\begin{array}{l}\text { Step } 2 \\
\text { T2 }\end{array}$ & Read T2 ... What do you think? Need more? & $\operatorname{Idem} \uparrow$ \\
\hline $\begin{array}{l}\text { Step } 3 \\
\text { T3 }\end{array}$ & Read T3 ...Idem $\uparrow$ & $\operatorname{Idem} \uparrow$ \\
\hline $\begin{array}{l}\text { Step } 4 \\
\text { T4 }\end{array}$ & Read T4 ...Idem $\uparrow$ & $\begin{array}{l}\text { Idem } \uparrow+\text { (if not previously raised) a question : } \\
\text { " same rate »: coincidence? } *\end{array}$ \\
\hline $\begin{array}{l}\text { Step } 5 \\
\text { T5 }\end{array}$ & Read T5 ...Idem $\uparrow$ & Idem $\uparrow$ \\
\hline $\begin{array}{l}\text { Step } 6 \\
\text { T6 }\end{array}$ & Read T6 ...Idem $\uparrow$ & $\begin{array}{l}\text { The interviewer is attentive to students } \\
\text { arguments, « mca » reactions, questions. } \\
\text { Strong input from interviewer. }\end{array}$ \\
\hline Final & Global evaluation of the design & Expressing feelings \\
\hline
\end{tabular}

*Here the interviewer asks for/provides the equations for decay and creation processes.

Table 2: Main steps in the teaching interviews.

\section{Style of interaction}

We referred to these interviews as "strongly structured and guided".

In the first steps of the intellectual pathway, often the interviewer's input is mainly aimed at better understanding what the students meant. But, for sake of focussing on his/her acceptance of an explanation, at times, the interviewer had to refrain from being too inquisitive about students' previous knowledge.

Int, 11, T1: So, do you think it's clear?

B, 12: $\quad$ Err, when we are asked, when they say that "A diagram $\ldots{ }^{14} \mathrm{C}$ will progressively disappear, according to a well defined process ..." So there, they don't give ...Yes, yes, I had read 
before, I think, perhaps a text like that. The thing I think is the most important is that, the living being, it absorbs all the time ${ }^{14} \mathrm{C}$, in order to have a stable level, in fact, and it is after the death that it starts decreasing.

Int, 13: $\quad$ OK, so the way you see

B, 14: otherwise we couldn't know really what is the starting point.

Int, 15: OK. Actually, how can you know it?

B,16: Err, I, we don't know it. Yes. Finally, there is nothing in the text that tells me that we know the starting point for ${ }^{14} \mathrm{C}$, but in contrast we know that the level started to decrease only when the living being in question died.

Int, 17: OK, it's how you understand this text, OK. Err, now I will show you a second text.

At certain steps in these interviews, the interviewer's comments may be very directive.

Int, 169, T6: Hum, just by looking at these equations, is there something that comes to mind?

A, 170: Hum it seems as if it transformed a neutron.

Int, 171: Ah yes, the budget is ...So there is something in these equations, so now, it's me who is going to give you some explanations, it is that, what you see during the formation process, actually, it is an atom of nitrogen which gives an atom of ${ }^{14} \mathrm{C}$. And during the process of destruction, of decay, it is ${ }^{14} \mathrm{C}$ which gives nitrogen.

A, 172: $\quad$ Hum

Int, 173: OK? So it means that the total number of ${ }^{14} \mathrm{C}$ and nitrogen, if I take them together, err, it remains constant, because either one transforms into the other, or the other transforms into the one.

\section{Processing and analysing the interviews}

The interview transcripts were submitted to a thematic content analysis, each category corresponding to a theme that can be identified in the students' comments. The data is processed using two types of categories. Some originate in our a priori analysis and others emerge from the transcripts (Strauss \& Corbin 1990). We pinpoint and count the occurrence of each category. This process was conducted independently by the two authors and the final classification emerged from a negotiation between them. Concerning the students' doubts and feelings, their comments will be extensively cited. All students' interventions are quoted using the first letter of his/her first name, the number of his/her comment in the progress of the interview and the step during which it was observed.

Our categories refer to both lines of analysis announced in our rationale.

\section{Conceptual aspects}

Concerning conceptual aspects, we underline that, due to the goal, structure and time constraint of the interview, we had to keep our priorities in mind and sometimes to renounce exploring students' previous ideas 
and reasons in depth. In this context of strong input from the interviewer or from the texts, we had to estimate which comments stemmed for students" "previous" knowledge.

We considered this was the case when they argued on a question that was not directly dealt with in a given text, or when they reacted strongly to what was written in a text. For instance:

Int, 162, T5: yes in fact I was just asking you to write the decay process

B, 163: $\quad$ Err it will turn into ${ }^{12} \mathrm{C}$, I think it will lose two neutrons, perhaps. Err ouh, grade 12, this!

$\mathrm{Y}, 12, \mathrm{~T} 1 \mathrm{I} \quad$ It (Text 1$)$ is consistent, it is just that I was not thinking that carbon, err So, if actually it transforms into ${ }^{14} \mathrm{~N} \ldots$

This said, we have to keep in mind that some ideas or lines of reasoning, be they correct or not, may have been shared by some interviewees who just didn't express these, given that they were not under pressure of an inquisitive dialogue about their knowledge of the topic.

The thematic categories that turned out to be the most productive for this analysis are shown in Table 3 . These categories are not exclusive.

The category "transient v/s stationary" was defined a priori, in relation to the common trends of reasoning recalled afore. Some difficulties about these aspects were expected from previous studies concerning the multiplicative aspect (Viennot, L. \& de Hosson 2012) and the transition between a transient and a steady state (Viennot, L., 2001; Colin, 2011; Besson et al., 2010). Sub categories (see Table 3) were deduced from our content analysis, which may involve complex frameworks. Categories A1 and A2 go with a non multiplicative line of reasoning, ending up with, respectively time rates depending only on individual probabilities (A1) which would be equal or not-, or only on equal numbers for both populations (A2). We also defined two other modalities of misunderstandings: the time rates of formation and of decay of ${ }^{14} \mathrm{C}$ have always been equal (A3), or they are equal just by chance (A4). In these two cases, we cannot analyze what concerns the "multiplicative" component, because these responses are not transparent enough in this respect.

We added to this list a category which emerged from the data. We have indeed observed a trend to think that ${ }^{14} \mathrm{C}$ decay product was ${ }^{12} \mathrm{C}$, a trend which seems to be part of a more general reciprocal contamination of chemistry and nuclear domains. Another students' view that we thought of interest is doubting that photosynthesis is isotope-dependent.

For the sake of compactness, the short descriptions displayed in Table 3 will be illustrated only in the section about results.

\begin{tabular}{|l|l|}
\hline Categories & Sub-categories \\
\hline A: Transient v/s stationary & $\begin{array}{l}\text { A1: not multiplicative: time rates of transformation } \\
\text { depend only on individual probabilities of } \\
\text { transformation: impossible steady state? or possible } \\
\text { in case of same probability }\end{array}$ \\
\cline { 2 - 2 } & $\begin{array}{l}\text { A2: not multiplicative: equal numbers for both } \\
\text { populations }\end{array}$ \\
\cline { 2 - 2 } & A3: Times rates have always been equal \\
\hline
\end{tabular}




\begin{tabular}{|l|l|}
\hline \multirow{2}{*}{ B: Chemistry v/s radioactivity } & A4: Equal time rates: by chance \\
\hline & B1: ${ }^{14} \mathrm{C}>>{ }^{12} \mathrm{C}$ \\
\hline & B2: Photosynthesis non isotope-dependent \\
\hline
\end{tabular}

Table 3: Main thematic categories used in the analysis of the interviews. Conceptual aspects.

Metacognitive-affective aspects

In relation to our main research question, concerning students' "intellectual dynamics", we examine how do students accept/reject partial explanations for the phenomenon under scrutiny. We focus on students' critical attitude, their awareness of their own comprehension, their intellectual satisfaction or frustration, aspects which are potentially entangled. We designate this conglomerate by "meta-cognitive-affective" aspects ( $m c a)$. More precisely, we pinpoint cases when they express their satisfaction of getting additional information about a topic $\left(\mathrm{m}^{+}\right)$, for instance

\section{A, 38, T2: I think it is what I was missing to know exactly how it works. I think I had forgotten.}

or, in contrast, when they express their frustration about insufficient explanation $\left(\mathrm{m}^{-}\right)$, for instance:

B, 103, T4: It poses a problem more than it solves ...

The level of their possible agreement at the end of the discussion of each given text is appreciated. It may be considered total (code in Table $4: \Theta$ ):

Int, 48, T3: (...) Is it clear? Is it sufficient? Are you still missing something to understand?

M,49: $\quad$ It's very complete.

or half-hearted (code in Table : $\approx$ ).

G, 14, T1: Well, is that sufficient ? Actually, it gives ... It doesn't explain everything, but actually it gives an idea, after that ...

Special attention is given to the type of question they pose during the discussion. A distinction is made between two types of questions.

Some questions bear on one of the "crucial items" listed in our content analysis. They are referred to as crucial questions (cq), thus:

B, 153, T5: Is that a necessity? Had it to reach a state of equilibrium, or is it just by chance that rates of formation and decay coincide? I 'm stuck!

J, 102, T4: ... Initially, this probability entailed that ${ }^{14} \mathrm{C}$, I mean the concentration of ${ }^{14} \mathrm{C}$ in the atmosphere increased, but then, why?

Other questions bear on a point which is not included in the list of crucial items (a "detail": dl), thus:

S, 52, T2: (...) but with a detector, yes, but how does it work, actually, the detector?

Among these "detail" questions we counted those which referred to the exact mathematical form of the decay function, beyond the fact that it had to be known:

$\mathrm{G}, 15$, T1: Err, just, when we ask, when they say "a process $\ldots{ }^{14} \mathrm{C}$ is going to disappear according to a well defined process ... So here, they don't give ...

At times, some questions were posed - and answered at once by the interviewer - about the meaning of a word, for instance "activity". In such cases, despite the crucial importance of knowing the meaning of these terms, the question is also coded "detail", given its purely technical aspect. 
The students' final intellectual satisfaction is referred to their ranking on a Likert scale (0: very low satisfaction, 4 very high). Significant comments will be quoted in extenso.

\begin{tabular}{ll}
\hline Thematic category $(\mathrm{mca})$ & Code \\
\hline Agreement at the end of a step & $\Theta$ \\
\hline Half-hearted agreement at the end of a step & $\approx$ \\
\hline Question posed about a detail & $\mathrm{Dl}$ \\
\hline Question posed about a "crucial" point & $\mathrm{Cq}$ \\
\hline Satisfaction after additional information & $\mathrm{m+}$ \\
\hline Frustration because of insufficient explanation & $\mathrm{m}-$ \\
\hline
\end{tabular}

Table 4: Main thematic categories concerning the meta-cognitive affective aspects. For the sake of compactness, the short descriptions displayed in the table will be illustrated only in the section on results.

Given our research target, what is considered relevant here are the features and chronology of students' possible changes in terms of " $m c a$ " aspect, in relation to the conceptual steps proposed in the successive texts. For sake of brevity, more detail concerning our relevant indicators in this respect will appear in the results section.

\section{Analysis of results}

\section{Conceptual aspects}

As mentioned above, the results in this area are a side product of our investigation. We gather in this section the results that seem particularly instructive and their analysis, within the limits of our research agenda.

-From transient to steady state

Concerning the transition from transients to steady states, the two first categories (A1\&A2 in Table 3), strongly involve a disregard of the multiplicative aspect. It is difficult to reason about multiplicative processes because at least two factors have to be considered simultaneously. Considering only one of the two factors - which means a "functional reduction" - has been found to be very common in many fields. Such an obstacle for example, was highlighted recently in optics (Viennot, L. \& Hosson, 2012).

Here, the production time rate is the product of the total nitrogen population by the individual probability of a conversion into a ${ }^{14} \mathrm{C}$ atom (related to the flux of cosmic neutrons). The fact that this formation time rate is constant is thus linked to the constancy or mutual inverse dependence of two factors: the flux of cosmic neutrons and the amount of nitrogen. But the latter is never mentioned in the students' responses.

The decay time rate is also multiplicative as it is the product of the total ${ }^{14} \mathrm{C}$ population by the individual probability of disintegration per unit time. Again, even if all students know this law, they don't make use of it. Disregarding the need to multiply individual probabilities by populations transforms the time rates into constant quantities and leads to two possible lines of reasoning (A1 and A2 in Table 3). Some students conclude that it is impossible to reach a steady state: 

B, 117, T4: I don't see any reason here that could explain [why the time rates are equal] since the
production just depends on cosmic radiation and since the disintegration just depends on its
constant, its half-life, its radioactive constant...

others that the steady state is possible only with equal individual probabilities of ${ }^{14} \mathrm{C}$ formation (from nitrogen) and decay:

V, 210, T5: In order to get exactly the same number, or a number almost identical... for me, it is that the probability of disintegration and creation are the same

Similarly, some students seem to think spontaneously, when discussing the analogy, that the only stable distribution of the two populations is necessarily 50/50 (A2 in Table 3). For instance:

S, 362, T6: We want a balance ... that is to say we want $50 \%$ of rurals and $50 \%$ of urbans?

Moreover, the fact that the distribution of ${ }^{14} \mathrm{C}$ and nitrogen steady is not 50/50 is noted by several students, which suggests that it might be a common thought:

Int, 202, T6: Exactly, we can say that evolution, it will continue until we reach that point.

B, 203: This here is not 50/50.

Two other sub- categories have been defined. The first one (A3 in Table 3) is reasoning as if the current steady state as described by Libby (two atoms are formed and two atoms decay) had always existed without any more arguments. This feature is very noticeable when students read the document presenting the fact that currently two ${ }^{14} \mathrm{C}$ atoms are created every second and two ${ }^{14} \mathrm{C}$ atoms disappear every second. Many of them seem to be surprised. For example:

T, 74, T4: Well if there are two atoms that are created and two atoms that disintegrate, well there is nothing after that to breathe.

Those students seem to implicitly assume that the steady state has always existed and that the initial ${ }^{14} \mathrm{C}$ population was zero.

The last sub-category (A4 in Table 3) is the belief that the equality of the production and decay time rates may be a coincidence. The fact that this equality is the result of an adjustment process seems to be ignored by most students. Three of them (10) think it's a coincidence .

$$
\text { T, 46, T3: Yes, well, it's a coincidence, but ... }
$$

or

G, 114, T4: Err for me, yes, it's a chance.

Five of them prefer not to comment on the issue. Only $2 / 10$ are clearly in favor of an adjustment process, one of them, however, justifying by a weak case:

Y,144, T5 : In general, everything tends to evolve toward a state of equilibrium

To sum up, this exploratory analysis shows that a prominent feature in students' comments during this interview is a strong disregard of the multiplicative structure of the processes under study. Eight on ten students may be considered as having, at one moment, forgotten one factor involved in a multiplicative 
process. Beyond this fact, the difficulties raised by the transition between transient and steady states have been illustrated under various modalities.

- Radioactivity and chemistry

Less expected observations led us to define a second category ( $\mathrm{B}$ in Table 3 ) gathering more specific aspects of radioactivity. Two modalities seem relevant:

B1: We noticed that only $2 / 10$ of the students interviewed knew that radiocarbon decays give rise to the formation of ${ }^{14} \mathrm{~N}$ (one of two students stating that he gave this answer "randomly"), $3 / 10$ said they did not know, and 5/10 (majority response) spontaneously think it will lead to the formation of ${ }^{12} \mathrm{C}$. The latter response may be explained by the fact that students know that ${ }^{12} \mathrm{C}$ is a stable carbon form.

T, 68, T3: Err 12 because carbon is stable and we want to say that the carbon-14 it will return to its stable form $[\ldots]$

However, one can also imagine that there is some sort of contamination of what is nuclear by what is chemical: in a chemical reaction, the number of protons of a carbon atom would be preserved. This lack of distinction between the field of chemistry and nuclear physics can lead to reversing the contamination of what should be chemical by what is nuclear (B2 in Table 3). Thus, some students seem to apply implicitly a rule stating that two isotopes of the same element do not have the same chemical properties.

S, 80, T3: But which type of carbon is used for photosynthesis then?

This assumption leads to a misunderstanding of the fact that carbon-14 is treated (in Libby's explanation) in the same way as carbon-12, as far as nutritional processes are concerned.

\section{B, 25, T2: [...] I was not convinced a priori that all living beings assimilated in the same way carbon-14 [as carbon-12]"}

These results, though limited they may be, pose the question of the non-obviousness of a separation between chemical and radioactive processes.

Meta-cognitive-affective aspects

The coding of students' interviews concerning $m c a$ aspects is displayed in Tables 5 and 6 . Table 5 displays students' level of agreement at the end of each step and the types of questions posed. Table 6 also displays their level of agreement but this time with the statements expressing satisfaction or frustration. Given our research question, we chose to rank the students in Table 5 according to the step during which they first posed a crucial question and we kept the same order for Table 6.

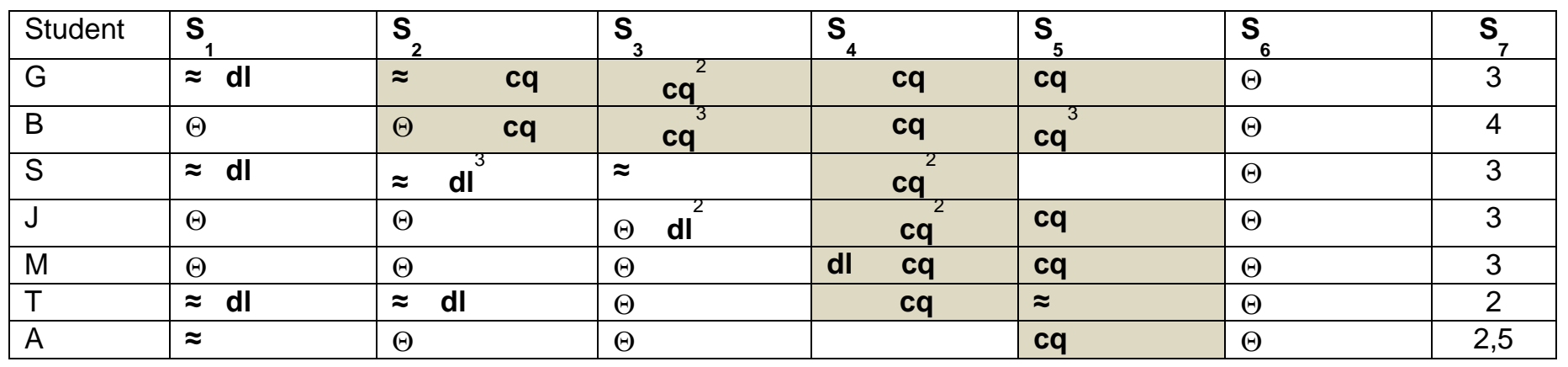




\begin{tabular}{|c|c|c|c|c|c|c|c|}
\hline $\mathrm{V}$ & $\Theta$ & $\Theta$ & $\Theta \quad$ dl & $\approx$ & $c q^{2}$ & $\Theta$ & 3 \\
\hline $\mathrm{Y}$ & $\approx \mathrm{dl}$ & $\Theta \mathbf{d l}$ & $\Theta$ & $\Theta$ & $\Theta$ & $\Theta$ & 4 \\
\hline $\mathrm{H}$ & $\Theta$ & $\approx \mathrm{dl}$ & $\Theta \quad \mathbf{d l ^ { 2 }}$ & $\Theta$ & $(\Theta)$ & $\Theta$ & 4 \\
\hline
\end{tabular}

Table 5: Level of agreement at the end of each step and type of questions posed.

Notations: $\Theta, \approx$ : agreement, half-hearted agreement; dl: question about «details "; cq: crucial question; $m+$ : satisfaction with a new piece of information; $m$ - : frustration. Last column: Likert scale from 1 (low) to 4 (high)

\begin{tabular}{|c|c|c|c|c|c|c|c|c|c|}
\hline Student & $\mathrm{S}_{1}$ & & $S_{2}$ & & $\mathrm{~S}_{3}$ & $\mathrm{~S}_{4}$ & $\mathbf{S}_{5}$ & $\mathrm{~S}_{6}$ & $\mathrm{~S}_{7}$ \\
\hline$G$ & $\approx$ & & $\approx$ & $m-$ & $m-$ & $m-$ & $m n^{2}$ & $\Theta \quad m+$ & 3 \\
\hline B & $\Theta$ & & $\Theta$ & $m+$ & $m+m^{2}$ & $m-$ & $m-$ & $\Theta \quad m+$ & 4 \\
\hline$S$ & $\approx$ & & $\approx$ & & $\approx$ & $m-$ & $m-$ & $m+$ & 3 \\
\hline$J$ & $\Theta$ & & $\Theta$ & $m+$ & $\Theta$ & $m-$ & $m-$ & $\Theta \quad m+$ & 3 \\
\hline M & $\Theta$ & & $\Theta$ & $m+$ & $\Theta$ & $m-$ & $m-$ & $\Theta \quad m+$ & 3 \\
\hline $\mathrm{T}$ & $\approx$ & $m-$ & $\approx$ & $m-$ & $\Theta$ & & $\approx m-$ & $\Theta \quad m+$ & 2 \\
\hline A & $\approx$ & & $\Theta$ & $m+$ & $\Theta \quad m^{2}$ & $m-$ & $m=$ & $\Theta \quad m+$ & 2,5 \\
\hline V & $\Theta$ & & $\Theta$ & & $\Theta$ & $\approx$ & $m-$ & $\Theta$ & 3 \\
\hline $\mathrm{Y}$ & $\approx$ & & $\Theta$ & $m+$ & $\Theta \quad m+$ & $\Theta$ & $\Theta$ & $m+$ & 4 \\
\hline $\mathrm{H}$ & $\Theta$ & & $\approx$ & & $\Theta$ & $\Theta$ & $(\Theta)$ & $\Theta$ & 4 \\
\hline
\end{tabular}

Table 6: Level of agreement at the end of each step and statements expressing satisfaction or frustration. Notations: $\Theta, \approx$ : agreement, half-hearted agreement; $m+$ : satisfaction with a new piece of information; $m-$ : frustration. Last column: Likert scale from 1 (low) to 4 (high)

Typical evolutions: the crucial " $V$ "

With the criteria we used to rank the students in Tables 5 and 6, the same in the two tables, and excluding the two last students ( $\mathrm{Y}$ and $\mathrm{H}$ ), we can observe that the same "diagonal" (broadly speaking, from col. 3 , line 2 to col. 6, line 9) divides the tables in two parts. Concerning the questions posed (Table 5), there is no surprise in finding only questions about details on the left of the diagonal because the table was constructed following this rule.

In contrast it is worth noting that, left of the same diagonal, what dominates the $m c a$ landscape is agreement or half-hearted agreement, despite the incompleteness of the explanations.

H, 10, T1: Err, there, it's enough for me, but if you ask me more precise questions, I will perhaps remember something else ...

J, 28, T1: No, err, it's rather clear too. We understand the principle at least.

V, 10, T1: Err, it explains the main points, after that, perhaps, I don't know, wait that I reread some parts, may be some would like more details [rereading the text] Err, No, for me yes, it gives the essential...

M, 20, T1: Yes, no, no, there are some good hints. It's true that it's very succinct, but you cannot give a whole course ... Err, no, no, it's clear, concise. (...) It's very complete.

Int, 43, T3: Is this still clear? Is it still sufficient, do you miss possible pieces of information or not?

T, 44: $\quad$ Err, no, that's enough for me.

In most cases of half-hearted agreement, students pose various questions about points which -from our point of view - are not crucial at this step: the way a detector works (irrelevant here), the exact mathematic 
expression of the law of decay (whereas in any case the starting point is needed), or what does the exponential function stem from:

S, 52, T2: Yes, yes, no, but quite, but with a detector, yes, but how does a detector works?

G, 15, T1: Err, only, when one asks, when they say that ${ }^{14} \mathrm{C}$ will disappear according to a well defined rule ....

Int, 16: They don't give the rule

G, 17: $\quad$ Yes

Int, 18: $\quad$ OK, they don't give the law of radioactive decay.

G, 19: $\quad$ That's it

Int, 20: $\quad$ That's all?

G, 21: $\quad$ Yes

H, 40, T2: Ah, err, we should explain, in this case (for beginners in this realm) where does it come from, the exponential law!

(...)

Int, 41: OK, Err, by and large, you are not missing any particular element, to

H, 42: $\quad$ No, no, everything is clear.

As for their comments expressing satisfaction or frustration (Table 6), we observe that with each text, in cases displayed left of the same diagonal, the students most often express their satisfaction for receiving new pieces of information, this without any real critique concerning the previous explanation:

A, 38, T2: I think it is what I was missing just now to know exactly how it works. I think I had forgotten..

B, 25, T2: There was a piece of information that I was just now wondering about, it's the proportion of ${ }^{14} \mathrm{C}$ which is the same in any living being. It's what I was wondering with the preceding text.

B, 30, T2: This one, err, it seems more precise.

B, 36, T2: Ok, this hypothesis, I don't know to which extent is it true or debatable, but at least, it is given.

A, 60, T3: This one, it's much more precise, I doubt, err, we don't necessarily need so much detail to understand the principle, it all depends on the degree of exigency that we have.

M, 44, T2: Err, I find the two texts finely complete each other. It's true that a little explanation of what does ${ }^{14} \mathrm{C}$ comes from, very short, like in the first text, it's cool, and after that how it's used for dating, in the second text, it completes well, I find. 
In contrast, on the right of the diagonal, in a " $\mathrm{V}$ " shaped domain of the tables, we observe no expression of agreement, and much frustration, along with crucial questions only.

B, 54, T3: It doesn't explain, it postpones the hypothesis a little further, on, "is the cosmic radiation constant or not?"

B, 103, T4: It poses a problem more than it explains.

Int, 135, T5: Actually it's not by chance. What is said in this text is that it's not by chance that there is a steady state.

A, 136: Err, in fact it doesn't really explain.

Int, 137: It doesn't really explain.

A, 138: It's not an explanation.

$(\ldots)$

A: $\quad$ (...) I have more questions (than at the beginning).

Int, 138, T4: Same thing, is it clear, is it sufficient, do you miss ...?

J, 139: It doesn't explain why...

Int, 140: $\quad$ Err

J, 141: Why it's (the time rates of formation and decay) equal?

This change from a docile approval to expressions of frustration may go together in students with an awareness of their previous attitude. Thus this ironical comment:

Int, 99, T4: Same thing, do you find it clear?

A, 100: It seems as if yes [laugh], ...given that I have not understood anything!

Such a comment shows an initial lack of critical stance, given the agreement previously expressed by the same student. But the same person, after a time of discussion and interactive text analysis, changes his/her attitude rather drastically in this respect.

Briefly put, these tables and the students' comments strongly suggest that at a given moment of the discussion, the interviewee appropriates the problem, becomes aware that a more complete explanation is needed, takes some distance vis à vis the texts under study, poses "crucial" questions and really starts arguing. Quite expectedly, there are some small fluctuations with regard to this typical evolution, actually in two cases. $\mathrm{T}$ expressed a frustration in step $\mathrm{T} 1$ and $\mathrm{T} 2$ before posing a crucial question in step $\mathrm{T} 4$, but his appreciation at the end of these first steps is a half-hearted agreement. Also, B acknowledged the interest of being given useful information still during step 2 - a step during which he first posed a crucial question-, but very soon in step 3 he twice expressed clear dissatisfaction.

Hypothetically, we might propose the idea that a certain development of the interviewee's conceptual understanding concerning the topic under study triggers the change that we just described. At this stage the students' comprehension of the topic may be still very incomplete, but with a better appreciation of some 
crucial aspects of the problem. As said above, given what we gave the most importance to in our methodology of investigation, we cannot directly focus on this conceptual enrichment. But it is undeniable that, along the interview, the texts provided to the students and the interaction with the interviewer can be considered as very likely to foster a conceptual progress in students, be it only an awareness of the complexity of the physical phenomenon in play.

It seems as if most students needed to reach a threshold of comprehension - not the same for all - before they felt a need for, and dared to, express their frustration. In that sense, we could speak of a co-development of conceptual understanding and critical attitude. Figure 2 illustrates graphically the very simple model of this hypothesis.

\section{Conceptual progress}

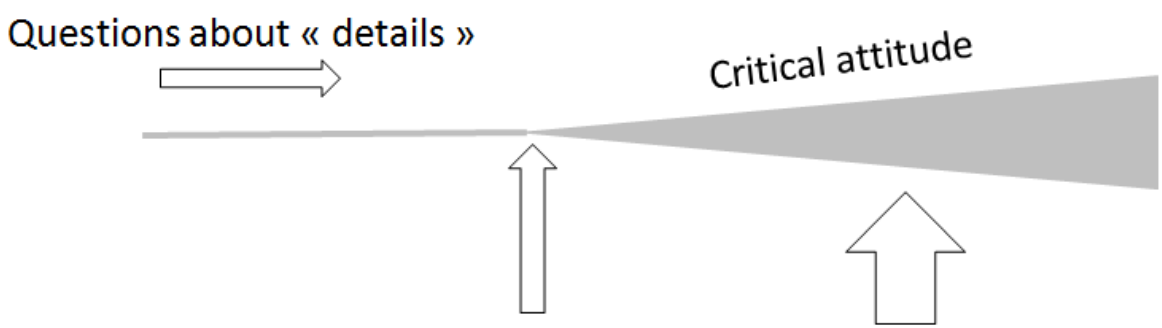

First crucial

question

Only crucial questions

Time

Figure 2: A tentative model for the co-development of conceptual understanding and critical attitude during the interviews.

In two cases only, the typical evolution described above does not fit in to our observations.

These students $(\mathrm{Y}, \mathrm{H})$ seem to be very uncritical towards the texts. They are also the ones who manifested the most advanced understanding of the topic, since the beginning. They posed no crucial question, as if they already had an answer for such questions.

\section{Step 6}

During step 6, the interviewer provided many tools, including the analogy outlined in Box 1, to reach a consistent comprehension of the topic. At the end of the interview, all of the students declared full agreement and a feeling of complete comprehension.

A, 220, T6: We have found why (...) why we reached a steady regime.

Int, 201, T6: So, still the same question, is it clear, sufficient, do you still miss some things to understand?

J, 202: $\quad$ Err, no.

Int, 203: You seem doubtful.

J, 204: No, no, I am surprised to have understood with a little diagram like that. 
$\begin{array}{ll}\text { Int, 205: } & \text { OK } \\ \text { J, 206: } & \text { But it's fine. }\end{array}$

Int, 191, T6: This time, does it answer all your questions or not?

G, 192: Yes, yes, the fact that it is constant.

It is noteworthy that all interviewees also declared no longer needing an answer to the "detail" questions they had previously posed, in particular concerning a more complete knowledge of the equations at stake:

Int 207, T6: Do you miss the equations?

J, 208: $\quad$ No, not even

Int, 209: Not even?

J, 210: We don't need them

S, 306, T6: It gives an answer to all my questions.

Int, 307: OK. Do you miss some equations or not?

S, 308: $\quad$ Not particularly.

This fact might be considered as a hint of conceptual achievement.

Intellectual satisfaction in final step

In the end, but not only (see above), strong satisfaction was expressed by all students.

In the case of the two students already cited (Y, H), their rating (4) was strongly connected to self-esteem, Thus:

Int, 289: Have you had a certain feeling of intellectual satisfaction during this interview?

H, 290: $\quad$ Err, yes, because I knew the answers!

Int, 291: $\quad$ OK

H, 292: It's good for our spirit but apart of that

Int, 293: If you had to say from 1 to 4,4 being the maximum ?

H, 294: $\quad$ Err, very proud of myself.

We also observe such a link with three students who rated their satisfaction respectively $2,2.5$ and 3 , arguing that they were dissatisfied with their answers but happy with the interview:

G, 226: No, err, I have learned some things but it's not thanks to me so for my personal satisfaction

Int, 227: Ah no, but any intellectual satisfaction is not necessarily...We have the right to

G, 236: No, intellectual satisfaction, it's when we are proud of (...). But apart from that I am satisfied. (rating 3) 

A, 308: $\quad$ Err, intellectual satisfaction, that is to say I am proud of myself? Not really
Int, 309: Not necessarily of you, but err
A, 310: $\quad$ Yes, I am happy to have learned some things (...)(rating 2.5)

This mitigated satisfaction may go with a touch of realism:

G, 234: I will say 3 (rating for intellectual satisfaction) because at this point, I have, everything is OK, I have understood, but I know I can forget it and not to be able to explain in my turn how ...

Thus five students clearly linked their intellectual satisfaction to self-evaluation - how brilliant or otherwise they were -, regardless of the fact that, in the end, they were happy to have understood the topic.

By contrast, the other students expressed their satisfaction (rated 3 or 4 ) in relation to their progress during the interview:

Int, 280: (...) Err, I would like to ask you whether you have felt some pleasure, say a kind of intellectual pleasure when discussing all this, or not at all?

B, 281: $\quad$ Yes, yes. Err I think I had never gone so far. We had done a little of this in grade 12 . Actually, there are more open questions than what we had seen.

$(\ldots)$

Int, 286: You had been told at that time that N0 was constant or not ?

B, 287: $\quad$ Yes, yes, yes

Int, 288: And no one had wondered why?

B, 289: $\quad$ No, err, this was not a big concern. Err, perhaps some people had... But me, I don't know if I had been shocked at that time (rating 4)

Int, 250: (..) Did you feel a kind of intellectual satisfaction during this interview, rated between 1 and 4 ?

M, 251: $\quad$ Yes I am satisfied

Int, 252: $\quad$ OK

M, 253: Yes, yes, I have had to think, I was asked my opinion. This said, it was very orientated this interview, no? We realize that we are given a text, and asked if it's OK. I say yes, it's OK. I am given another text. Ah yes, the first one was not sufficient. Then you give me a diagram. Ah yes the preceding texts were not sufficient. But yes, after that, yes, there are a lot of things that fall into place, I managed to understand some notions that seem a little obscure, that I will perhaps have difficulties to explain; yes I am satisfied, so between 1 and $4,(\ldots)$ I will say 3 .

To sum up, the term intellectual satisfaction was differently interpreted according to the students, more or less in relation to their self-esteem. All students were happy to have understood the topic, with sometimes a touch of doubt about their ability to explain it to someone else. Interestingly, most of them express willingly what they have perceived of their intellectual pathway, their first mild agreement, the way they reconsidered their first responses, and their satisfaction that "a lot of things" had finally "come into place". We see this metacognitive-affective standpoint as a clue of their conceptual progression.

\section{Recapitulation and final remarks}


This paper is centered on the relationships between students' conceptual development and their critical stance relating to very incomplete explanations. We conducted this investigation keeping in mind the possible implication of students' intellectual satisfaction in their progression. We would like to stress the novelty of our methodological approach which consists in presenting students with a series of explanations of progressive completeness, starting with a very incomplete one. This setting permits a progressive probing of students' critical disposition. To our knowledge, this type of research setting has not yet been reported on in physics education research. We also underline the intrinsic difficulty we met, i.e. having some access to student's personal ideas on the conceptual domain without screening the steps of his/her metacognitiveaffective pathway.

We took the topic of radiocarbon dating, because it was likely to sound familiar to our interviewees - ten prospective teachers - while being in fact rather complex. Consistently, this investigation is informative on both levels, conceptual and metacognitive-affective ( $\mathrm{mca}$ ), knowing that we encapsulate in this compound label students' degree of awareness of their own intellectual progression, their satisfaction or frustration at different steps, and their critical faculty.

Given our primary goal - the possible co-development of their conceptual understanding and critical faculty-, we had to avoid too inquisitive an evaluation of their previous comprehension of the topic, not to overdetermine their responses to the explanations subsequently analysed. However, we collected substantial hints of what were their previous ideas and lines of reasoning about the topic in play. We consider these preliminary results as useful guides for preparing a possible investigation on students' ideas and ways of reasoning about radiocarbon dating, a topic which is not documented in the research literature.

Some of these preliminary results were quite expected. Such is the case of students' reduced consideration of multiplicative processes, consisting in bringing to bear, de facto, only one of the two relevant factors. Nearly all students showed this trend, be it when dealing with the possible change in total population of radiocarbon or with the time rate of radio-decay. More specific tendencies seem to have hindered students' comprehension of the existence of two regimes, a transient one and a steady state, in the interaction between the populations of ${ }^{14} \mathrm{C}$ and ${ }^{14} \mathrm{~N}$. Among the observed difficulties was the idea that if the time rates of formation and decay of ${ }^{14} \mathrm{C}$ are equal, it is just by chance. It also happened that the time-rates of exchange are seen as always having have been equal as in the steady state, which means that starting from zero a given population could not increase.

Less expected were some responses that we rank under the label "reciprocal contamination" between chemistry and radio-processes. Thus we found that, for half of this sample of students, radiocarbon decayed into normal carbon, as if the corresponding "element" - carbon - was to be conserved. On the other hand, some students posed the legitimate question of an isotopic dependence of photosynthesis, other nutritional processes and respiration, which are chemical processes.

Turning now toward students' critical faculty, it might be said that, given all these conceptual difficulties and their deficient knowledge, students could not react to any insufficient explanation of radiocarbon dating. But this is not necessarily the case. Indeed, there is no need to understand how radiocarbon dating works to ask, after the most incomplete text, why there should be no radiocarbon decay in the atmosphere, or to wonder, after a more elaborate text, why the formation and decay rates of radiocarbon would be equal, or else to reject the idea that it is just by chance. On this basis, we suggest that the chronology of students' first crucial questions and critical statements constitutes a relevant hint for our research target.

We wish to underline that we are not searching for correlations between students' conceptual achievements, on the one hand, and their critical faculty, on the other, both aspects referring to a given "state" of students' intellect. What we looked to document was a process of co-development of conceptual understanding and 
critical faculty. We have not directly evaluated students' conceptual development, not to interfere too much with their meta-cognitive and affective evolution. Therefore, we speak of conceptual development as a phenomenon which is likely to occur, given the time elapsed since the beginning of the interview and the enrichment of students' and interviewer's argumentation. Concerning the latter aspect - critical faculty -, we are interested in the way students activate or not their potential of response to an intellectual frustration.

For most of the interviewees, the first phase in the interaction is characterized by a mild agreement of very incomplete explanations, often with vague recognition of old memories that they were happy to be reminded of, and various questions they posed in order to complete this remembering process. Then, for a reason that is not directly identified, they pose a question which relates to a crucial element of the targeted line of reasoning. This is the starting point of a phase of very active discussion during which no agreement is expressed vis-à-vis the texts under study ( $\mathrm{Tn}$ with $\mathrm{n}<6)$. Instead, a series of crucial questions is posed, giving the impression that the student appropriates the search for a consistent explanation, while expressing more or less clearly his or her dissatisfaction. This suggests that a threshold of comprehension, student-dependent, has to be reached in order to free interviewees' critical potential, so that a search for intelligibility replaces a search for memories.This description converges with previous findings quoted in the introduction (Viennot, L., 2006; Mathé \& Viennot, L., 2009; Feller et al., 2009), which show important delays between the beginning of the interaction under study and the triggering of interviewees' or pupils' critiques.

This said, the idea of "threshold" introduced here needs further specification. Would a particular conceptual knowledge be logically indispensable to understand that there is a problem with such and such an explanation, then it would be somewhat obvious that students should reach this level of conceptual comprehension to be able to critically react. The threshold in play would be conceptual, and it would first open a route to a conceptual progress. Then we would be in a perspective rather similar, although at smaller scale, to that of the "threshold concepts" defined in the phenomenographic line of research by Meyer and Land (2003). It may be also noted that the dissatisfaction we observe here echoes the "troublesome" nature of Meyer and Land's "threshold concepts". But the description we propose for the observed interaction is different. Students would need to reach a threshold of conceptual comprehension, higher than what is logically indispensable, that would give them access to a new attitude, actually to a critical moment combining dissatisfaction, questioning and critical stance. Strong intellectual satisfaction would often follow - result from? - this critical phase, but would intervene after new conceptual inputs on behalf of the interviewer.

Though subtle this discussion may appear, it seems worth exploring and clarifying further. Very probably, there are psychological components, such as self-esteem, a factor perceptible in half of our sample, or feelings of (in)security that might contribute explaining such a phenomenon, in conjunction with cognitive ones. Given this very complex psychocognitive landscape, it is probably unrealistic to decide at which very precise moment, and because of which factor, the critical phase is triggered in a given student, even if, in some cases, it is tempting to analyse student's comments in these terms.

A few cases in our sample (2/10) do not straightforwardly illustrate the typical pathway just described. These students - "experts" in what follows -, previously knew the targeted explanation very well. They posed hardly any question, being permanently satisfied with themselves and very tolerant toward the text. The uncritical phase actually lasted during the whole interview, whereas no strong concern was observed about missing memories. These cases suggest that reaching a (student-dependent) threshold of comprehension is a necessary condition for enacting a critical faculty, but not a sufficient one. Again, we have to admit that the conceptual aspect is not the only one to be considered in search for the determinants of a critical attitude. Such phenomena of blockages of critical faculty in "experts", in other words of "anesthesia of judgment", have 
already been observed in teachers and analyzed (Viennot, L., 2006). For instance, if a hot air balloon is nearly always presented as isobaric (see for instance Giancoli 2005) when it comes to calculate the internal temperature needed for take off, it is not because the textbook writers or teachers ignore the law of fluid statics.We need a better understanding of these phases of critical passivity observed in more or less "expert" students of teachers. For instance, in the case of the hot air balloon, the only fact that this inconsistent hypothesis leads to a correct solution via a calculation of Archimedes' up-thrust may be sufficient to block any criticism. Among other assumptions that present themselves, experts may mentally complete the explanations they are presented with without being aware of this process. Or their feeling of conceptual achievement and their self-esteem might screen any concern about the texts under study.

To sum up, concerning students who start an interaction with a very limited conceptual command of the subject broached, a blocking factor might be their search for vanishing memories, which prevails in the first steps of the interactive pathway. The threshold of comprehension that seems to go with a liberation of students' critical potential appears also as a threshold of intellectual dissatisfaction. This type of intellectual process cannot be explained, we think, on the basis of a competence - critical faculty - that would be there or not in the students' panoply of intellectual tools, a viewpoint already challenged by, for instance, Willingham (2007). The way a given potential of critique is enacted or not may strongly depend on students' evolving comprehension of a topic in conjunction with some psychological aspects, and, reversely, this potential is likely to develop via intellectual pathways which involve conceptual as well as meta-cognitive and affective aspects. As for experts' lack of critical activity, when observed, several processes may intervene, from unconscious complementing of the text under scrutiny to exclusive focus on their own successful comprehension. The stability of many teaching rituals (Viennot, L. 2006) might be seen as another consequence of such factors of critical passivity.

All these hypotheses are still speculative and further research is needed to appreciate their validity.

For both populations - current students or experts -, factors that confer an apparent value to an incomplete explanation should also be investigated in more detail, beyond the well-known "one-cause-is-enough" syndrome. Overall, the role played by the search for intellectual satisfaction in the liberation of one person's critical potential, this possibly at the expense of more protective strategies, remains a whole field of research still widely unexplored. It is striking that in his definition of various learning styles, Vermont (1996) associates "critical processing" of a given content to only one of these styles, a "meaning oriented learning style", and that it is only in this category that he mentions the pleasure to learn. Here also, we observe an association between activation of critical processing and (search for) intellectual satisfaction. We do not use this co-occurrence to define a learning style but rather to designate a step that has been reached -actually by most of our interviewes - in a given pathway. Clearly, a vivid question is how to favour such a process.

In terms of educational settings, the questions broached above should be further documented, we think, in order to better inform political decisions about priority objectives to be ascribed to science education: competences or (and) conceptual development? Despite the limited character of this study, our analysis provides strong arguments against the thesis that we might develop critical faculty in our students independently of a conceptual education. There is still much research to carry out to inform the question of how to manage the interplay between these two components in science education. We suggest that this question would be fruitfully addressed with an explicit focus on students' intellectual dynamics, in other terms the co-development of their conceptual understanding and critical stance, this in various teaching learning contexts. 


\section{References}

Besson, U., De Ambrosis, A. \& Mascheretti, P. (2010) Studying the physical basis of global warming: thermal effects of the interaction between radiation and matter and greenhouse effect, European Journal of Physics, 31, 375-388. doi:10.1088/0143-0807/31/2/015

Colin, P. (2011). Enseignement et vulgarisation scientifique : une frontière en cours d'effacement ? Une étude de cas autour de l'effet de serre [education and scientific popularization: a border which tends to deseapear?: a case study about greenhouse effect]. Spirale, 48, 63-84. Retrieved from http://spirale-edurevue.fr/spip.php?article1081

DiSessa A.A. (1983). Phenomenology and the Evolution of Intuition. In D. Gentner and A.L. Stevens (Eds) Mental Models (pp. 15-33), Hillsdale, New Jersey: Lawrence Erlbaum

DiSessa, A.A. (2008). A Bird's-Eye View of the "Pieces" vs. "Coherence" Controversy (From the "Pieces" Side of the Fence), In S. Vosniadou (Ed.) International Handbook of Research on Conceptual Change (pp.35-60), New York: Routledge.

Driver, R., Guesnes, E. \& Tiberghien, A. (1985). Some features of Children's Ideas and their Implications for Teaching, In R. Driver, E. Guesne and A.Tiberghien (Eds): Children's Ideas in Science, pp. 193-201. Milton Keynes, UK: Open University Press.

Duit R. (2009). Bibliography STCSE, Students' and Teachers' Conceptions and Science Education. Retrieved from http://archiv.ipn.uni-kiel.de/stcse/

Ennis, R. H. (1992). The degree to which critical thinking is subject specific: Clarification and needed research. The generalizability of critical thinking: Multiple perspective on an educational ideal, Edited by: Norris, S. pp. 21-37. New-York: Teachers College Press.

Fauconnet, S. (1984). Etude de résolution de problèmes analogues, In A.Tiberghien 1984 (Ed.), Research on physics education : proceedings of the first international workshop,La Londe les Maures 1983. pp. 261269. Paris : CNRS

Feller, I., Colin, P. \& Viennot, L. (2009) Critical analysis of popularisation documents in the physics classroom. An action-research in grade 10. Problems of education in the 21st century, 17, 72-96. Retrieved from http://journals.indexcopernicus.com/abstract.php?icid=900326

Flavell, John H. (1987). Speculations about the nature and development of metacognition. In F. E. Weinert \& R. Kluwe (Eds.), Metacognition, motivation, and understanding (pp. 21-29). Hillsdale, N.J.: L. Erlbaum Associates.

Furtak, E.M., Seidel, T., Iverson, H.\& Briggs, D.C. (2012). Experimental and Quasi-Experimental Studies of Inquiry-Based Science Teaching : A Meta-Analysis, Review of Educational Research, 84, 300-329. doi:10.3102/0034654312457206

Giancoli, . D.C. (2005). Physics (6th ed): Instructor Resource Center CD-ROM, Prentice Hall

Gunstone, R.F. (1994). The importance of Specific Science Content in the Enhancement of Metacognition. In P. Fensham, R.F. Gunstone and R. White (eds). The Content of Science: A Constructivist Approach to its Teaching and Learning (pp.131-146). London: The Falmer Press.

Habermas, J. (1981). The theory of communicative action. Boston: Beacon Press.

Jenkins, E. W. (2007). School science: A questionable construct? Journal of Curriculum Studies, 39, pp. 265282. doi:10.1080/00220270701245295

Jiménez-Aleixandre, M. P. (2007). Designing Argumentation Learning Environments. In S. Erduran., \& M. P. Jiménez-Aleixandre. (Eds.). Argumentation in science education: Perspectives from classroom-based research (pp. 91-115). New York: Springer. doi:10.1007/978-1-4020-6670-2 
Jiménez-Aleixandre, M.P. \& Erduran, S. (2007). Argumentation in Science Education: An Overview, In S. Erduran and M. P. Jimenez-Aleixandre (Eds) Argumentation in Science Education Perspectives from Classroom-Based Research, 3-28, Dordrecht: Springer. doi:10.1007/978-1-4020-6670-2

Jiménez-Aleixandre, M.P. \& Puig, B. (2009). Argumentation, Evidence Evaluation and Critical Thinking. In B.J. Fraser, K. Tobin \& C. McRobbie, Second International Handbook of Science Education, pp. 10011015. Dordrecht: Springer. doi:10.1007/978-1-4020-9041-7

Kattmann, U., Duit, R., GropengieBer, H. and Komorek, M. (1996). Educational reconstruction - bringing together issues of scientific clarification and students' conceptions. Paper presented at the annual meeting of the National Association of Research in Science Teaching, St Louis, MO, April. Retrieved from http://www.researchgate.net/profile/Ulrich_Kattmann/publication/271958515_Educational_Reconstructio $\underline{\mathrm{n}}$ _Bringing_together_Issues_of_scientific_clarification_and_students_conceptions._NARST_1996/links/ 54d731660cf25013d036c802.pdf

Kirschner, P.A., Sweller, J. \& Clark, R.E. (2006) Why Minimal Guidance During Instruction Does Not Work: An Analysis of the Failure of Constructivist, Discovery, Problem-Based, Experiential, and Inquiry-Based Teaching. Educational Psychologist, 41, 75-86. doi:10.1207/s15326985ep4102_1

Komorek M. \& Duit R. (2004). The teaching experiment as a powerful method to develop and evaluate teaching and learning sequences in the domain of non-linear systems, Internatinal Journal of Science Education, 26, 619-633. doi:10.1080/09500690310001614717

Kuhn, D. (1991). The skills of arguments. Cambridge (UK): Cambridge University Press.

Libby, W. F. (1964), Nobel Lecture: Radiocarbon Dating. In Nobel Lectures, Chemistry 1942-1962. Amsterdam: Elsevier Publishing Company.

Marton , F. \& Booth, S. (1997). Learning and awareness, Mahwah, NJ: Erlbaum, Psychology Press.

Marton, F. (1981). Phenomenography: Describing conceptions of the world around us, Instructional Science, 10, 177-200. doi: 10.1007/BF00132516

Marton, F. (1986). Phenomenography-A research approach to investigating different understandings of reality. Journal of Thought, 21, 28-49.

Mathé, S., \& Viennot, L. (2009). Stressing the coherence of physics: Students journalists' and science mediators' reactions, Problems of education in the 21st century. 11, 104-128. Retrieved from http://journals.indexcopernicus.com/abstract.php?icid=886218

McPeck, J. (1981). Critical thinking and education. New York: St Martin's Press

Meyer, J. H. F. \& Land, R. 2003. 'Threshold Concepts and Troublesome Knowledge 1 - Linkages to Ways of Thinking and Practising' in Improving Student Learning - Ten Years On. C. Rust (Ed), Oxford: OCSLD. Retrieved from: http://www.colorado.edu/ftep/documents/ETLreport4-1.pdf

Minner, D. D., Levy, A.J., Century, J. (2009). Inquiry-Based Science Instruction-What Is It and Does It Matter? Results from a Research Synthesis Years 1984 to 2002. Journal of Research In Science Teaching, 47, 474-496. doi:10.1002/tea.20347

Moore, T. (2004) The critical thinking debate: how general are general thinking skills?, Higher Education Research \& Development, 23, 3-18. doi:10.1080/0729436032000168469

National Research Council. (1996). The National Science Education Standards. Washington, D.C.: National Academy Press.

Ogborn, J. (1997). Constructivist metaphors of learning science. Science \& Education, 6, 121-133. doi: 10.1023/A:1008642412858

Osborne, J.. Dillon, J. (2008). Science Education in Europe : Critical Reflexions. Nuffield Foundation. www.nuffieldfoundation.org/sites/default/files/Sci_Ed_in_Europe_Report_Final.pdf

Perkins D. N., Farady N. \& Bushey N. (1991). Everyday reasoning and the roots of intelligence. In : J. F. Voss, D. N. Perkins et J. W. Segal, (éds.), Informal Reasoning and Education, Hillsdale, NJ : Erlbaum, 83-105. 
Rocard, Y., Csermely, P., Jorde D., Lenzen D., Walberg-Henriksson, H., Hemmo, V. (2007). Science Education Now: A Renewed Pedagogy for the Future of Europe. Report EU22-845, Brussels: European Commission.

Rozier, S. \& Viennot, L.. (1991). Students' reasoning in elementary thermodynamics, International Journal of Science Education, 13, 159-170. doi:10.1080/0950069910130203Strauss A. \& Corbin, J. (1990). Basics of Qualitative Research: Grounded Theory, Procedures and Techniques. Newbury Park, Calif: Sage publications.

Vermunt, J.D. (1996). Metacognitive, cognitive and affective aspects of learning styles and strategies: A phenomenographic analysis, Higher Education, 31, 25-50. doi: 10.1007/BF00129106

Viennot, L. \& de Hosson, C. (2012). Beyond a dichotomic approach: the case of colour phenomena. International Journal of Science Education, 34, 1315-1336. doi:10.1080/09500693.2012.679034

Viennot, L. (1988). Tendance à la réduction fonctionnelle: obstacle au savoir scientifique et objet de consensus. In Construction des savoirs. Obstacles et conflits., N. Berdnaz et C.Garnier eds., CIRADE, Université du Québec, Montréal, 84-92.

Viennot, L. (2001). Reasoning in physics (chap. 5), Dordrecht: Kluwer

Viennot, L. (2006). Teaching rituals and students' intellectual satisfaction, Physics Education, 41, 400-408. doi:10.1088/0031-9120/41/5/004

Vosniadou, S. (2002). On the nature of naïve physics. In M. Limon \& L. Mason (Eds.), Reconsidering conceptual change: Issues in theory and practice (pp. 61-76). Dordrecht: Kluwer. doi:10.1007/0-306-47637-1 3

Walton, D.N. (1996). Argumentation schemes for presumptive reasoning; Mahwah, N.J.: Lawrence Erlbaum. Willingham, D.T. (2007). Critical thinking Why is it so hard to teach ? American Educator, 1-19. Retrieved from: http://www.aft.org/sites/default/files/periodicals/Crit_Thinking.pdf

Zohar, A. \& Barzilai, S. (2013) A review of research on metacognition in science education: current and future directions, Studies in Science Education, 49:2, 121-169. doi:10.1080/03057267.2013.847261 